DURÁN, Mario. “Justificación y legitimación político-criminal de la pena. Concepto, criterios y orientaciones en la actual jurisprudencia nacional".

Polit. crim. Vol. 4, No 8, (Diciembre 2009), Art. 1, pp. 266-291 (1-26).

[http://www.politicacriminal.cl/Vol_04/n_08/Vol4N8A1.pdf]

\title{
Justificación y legitimación político-criminal de la pena. Concepto, criterios y orientaciones en la actual jurisprudencia nacional.*
}

\author{
Dr. Mario Durán Migliardi. \\ Profesor de Derecho Penal y Criminología \\ Universidad de Atacama \\ mario.duran@uda.cl
}

\section{Resumen}

El presente artículo, en el marco de las teorías de la pena, busca establecer el criterio mayoritario que nuestra jurisprudencia reciente emplea para aplicar y justificar la sanción penal. En este sentido, basándose en el análisis de la teoría de la pena que subyace o reconoce el actual Código Penal chileno, plantea la existencia de un criterio mayoritariamente retributivo, proporcional y ligado al juicio normativo de reproche, para legitimar la aplicación de la misma.

Palabras Clave: Fines de la pena, Individualización judicial de la pena, Retribución, Código Penal.

\begin{abstract}
This article, written within the framework of penal theories, seeks to establish the most widely applied criterion used by our recent jurisprudence in the application and justification for penal sanction. In this respect, and based on the analysis of the penal theory that underlies and is recognized by the current Chilean Penal Code, this article proposes the establishment of a criterion which is mainly compensatory, proportional and linked to the normative judgment of guilt to legitimize its application.
\end{abstract}

Key words: Purposes of punishment, Judicial individualization of punishment, Retribution, Penal Code.

\footnotetext{
* Este trabajo ha sido realizado en el marco del Proyecto de iniciación en Investigación Conicyt-Fondecyt $2007 \mathrm{n}^{\circ} 11075088$, titulado "Justificación y legitimación de la pena en el Derecho penal chileno. Análisis desde el modelo integral de la ciencia jurídico-penal", de quien el autor es investigador responsable. En la realización de la recopilación jurisprudencial ha sido fundamental el trabajo y apoyo técnico del Licenciado en Ciencias Jurídicas de la Universidad de Atacama don Ramón Beltrán Calfurrapa.
} 
DURÁN, Mario. “Justificación y legitimación político-criminal de la pena. Concepto, criterios y orientaciones en la actual jurisprudencia nacional".

\section{Introducción y delimitación del tema.}

Hoy constituye un paradigma señalar que cualquier análisis de la evolución de la metodología del Derecho penal queda trunco si no se incluye en él, a lo menos, un breve examen sobre el aspecto más relevante de la denominada Teoría de la Pena, esto es, los llamados Fines de la Pena. ${ }^{1}$ Por ello, ambos problemas -metodología y fines de la pena- se han establecido como puntos básicos y obligatorios a la hora de abordar cualquier discusión, estudio o reflexión sobre Derecho penal, que discurra sobre la cuantía, entidad, fin, gravedad y/o justificación del castigo penal.

Más aún, es justamente en éste último punto -el de la justificación de la pena- donde la Teoría de los fines de la pena tiene, a mi juicio, su mayor relevancia. Ello, porque, desde antiguo, el Estado, la Iglesia o los pensadores, han buscado una teoría que cumpla con el objetivo de justificar, ante la sociedad civil y sus conciencias, la ejecución, históricamente atroz e inhumana, del castigo penal.

De este modo, la justificación, la idea de la función y del fin, ha sido el motor que ha movido a la humanidad ha buscar la teoría que justifique la causación del mal que implica la pena penal, puesto que, como bien se señala, "de ello depende, en definitiva, el sentido y la tarea del Derecho penal". 2

Por estas razones, la pregunta acerca del sentido de la pena estatal se plantea como nueva en todas las épocas. En efecto, este tema no trata sólo de un problema teórico, ni de vanas reflexiones sobre el sentido de ésta o aquella manifestación de la vida, sino de un tema de acuciante actualidad práctica, sobre todo en nuestra realidad Latinoamericana. Esto es, sobre ¿cómo y bajo qué presupuestos puede justificarse que el grupo de hombres asociados en el Estado prive de libertad a alguno de sus miembros o intervenga de otro modo, conformando su vida, en su existencia social?

De esta forma, quien analiza este tema, no se puede contentar o dar por satisfecho con las antiguas respuestas dadas a estas interrogantes, ya que la situación histórico-espiritual, social y constitucional del respectivo presente exige nuevas respuestas. ${ }^{3}$

Así, a mi juicio, el análisis del tema de los fines de la pena y de la justificación del Derecho penal, no implica permanecer atado a las antiguas y ya superadas teorías sino justamente intentar avanzar a través de los nuevos caminos abiertos para tales efectos por la doctrina penal. Más aún cuando dicho análisis se inicia, como es en esta propuesta, desde un concepto de pena que la sitúa como un mal, como una lesión o restricción de derechos o

\footnotetext{
1 Así, GARCÍA PABLOS, Antonio, "Tendencias del actual Derecho penal" en, AA.VV., Modernas tendencias en la ciencia del Derecho penal y en la Criminología, Madrid: UNED, 2001, pp. 39 y ss; BOTTKE, Wilfried, "La actual discusión sobre las finalidades de la pena" en, SILVA SÁNCHEZ, JesúsMaría, (Edit.) Política criminal y nuevo Derecho penal. L.H. a Claus Roxin, Barcelona: Bosch, pp. 41 y ss. ${ }^{2}$ CEREZO MIR, José, Curso de Derecho penal español, Parte General, Madrid: Tecnos, 1992, p. 21.

${ }^{3}$ En este sentido, por todos, Cfr. ROXIN, Claus, "Sentido y límites de la pena estatal" en su Problemas básicos del Derecho penal, Madrid: Reus, 1976, p. 11.
} 
Polit. crim. Vol. 4, No 8, (Diciembre 2009), Art. 1, pp. 266-291 (1-26).

[http://www.politicacriminal.cl/Vol_04/n_08/Vol4N8A1.pdf]

bienes jurídicos, respecto de aquél sujeto que supuestamente ha cometido algún delito y se le pretende imputar su responsabilidad jurídico-penal.

Por ello, en el marco de este aporte, que constituye un primer y parcial acercamiento al objeto de que trata el estudio Fondecyt-Conicyt, en el cual se enmarca, desarrollaré los resultados que se han obtenido en la búsqueda del criterio dominante en nuestra actual jurisprudencia sobre los fines de la pena.

\section{El concepto de pena del cual se parte.}

Hoy constituye un principio ampliamente aceptado en la doctrina penal que la comisión de un hecho ilícito tiene como consecuencia directa la imposición, por parte del Estado, de una pena o de una medida de seguridad con el objeto de hacer efectivas las distintas funciones que la sociedad y el propio Estado han determinado para el Derecho penal.

Dichas funciones, por su parte, corresponden, esencialmente, a las de constituir un medio de dirección y de control social formal y a las de ser, desde la óptica de los sujetos afectados directamente por el delito, un medio o mecanismo de reparación del mal o daño causado.

Este concepto general del Derecho penal implica que tanto los actos jurídico-legislativos de establecimiento de delitos como los de aplicación de penas y/o medidas de seguridad -que, según el criterio mayoritario, sólo pueden ser las post-delictuales- sean el rasgo característico, esencial o estructural, del Derecho penal moderno. Razón por la que se señala que hasta ahora ningún Estado ha podido renunciar a la pena como causación consciente de un mal para garantizar el orden jurídico ${ }^{4}$ y que ésta sigue siendo un recurso al que debe acudir el Estado para posibilitar la convivencia entre los hombres. ${ }^{5}$

Por ello, a mi juicio, el concepto de pena y la forma de plantear su justificación, su función así como los fines que se le atribuyan, resultan de una importancia fundamental para el Derecho penal, ya que de tales ideas emanan, a su vez, los criterios según los cuales la sociedad y, especialmente, los operadores jurídicos realizan la enseñanza, la aplicación y el análisis de todo el sistema del Derecho penal. Existiendo una clara relación entre el tipo de sociedad y el régimen político; el concepto de pena, su justificación y sus fines; y la forma de enseñanza y aplicación del sistema del Derecho penal.

\footnotetext{
${ }^{4}$ En este sentido, JESCHECK, Hans-Heinrich, Tratado de Derecho Penal. Parte General, $4^{\mathrm{a}}$ Ed. Granada: Comares, 1993, p. 57. Grafican esta idea los ejemplos y las observaciones que el autor acompaña a su afirmación; "El Código criminal sueco de 1962 ha regresado a la pena después de que el Proyecto de 1956 pretendiera sustituir tal expresión por el vocablo neutro 'consecuencia jurídica'...Precisamente en países con una Política criminal avanzada, como Suecia y California, se observa un regreso desde la ideología del tratamiento hacia la pena".

5 GIMBERNAT ORDEIG, Enrique, “¿Tiene futuro la dogmática jurídicopenal?” en Estudios de Derecho penal, Madrid: Civitas, 1976, pp. 57 y ss. Y, en Problemas actuales de las ciencias penales y la filosofía del Derecho. L.H. al profesor Luis Jiménez de Asúa, Buenos Aires: Pannedille, 1970, pp. 595 y ss.
} 
DURÁN, Mario. “Justificación y legitimación político-criminal de la pena. Concepto, criterios y orientaciones en la actual jurisprudencia nacional".

Así, el concepto de pena desde el que inicio este análisis, se basa en dos conceptos de la misma que estimo directamente relacionadas. La idea de la pena como una "amarga necesidad dentro de la comunidad de seres imperfectos como son los hombres", que corresponde al concepto de pena establecido por el Proyecto Alternativo de Código Penal alemán de 1967 -Alternativ Entwurf- y el concepto material de pena, según el cual, ésta es una privación o restricción de bienes jurídicos. ${ }^{6}$

En mi opinión, ambos conceptos se relacionan, sobre todo, en el hecho que destacan, describen o señalan a la pena como un mal, como una privación o como una restricción, ${ }^{7}$ lo que implica redescubrir lo negativo que supone la imposición de la pena a cualquier miembro de la sociedad. Cuestión ésta desde la cual estimo fundamental iniciar el camino del análisis de las teorías de la pena, más aún cuando lo que se pretende es dejar de manifiesto lo que se esconde tras las distintas justificaciones acerca de los fines y objetivos de la pena. ${ }^{8}$

Por lo mismo, estimo también que resulta insuficiente detenerse, solamente, en la constatación del hecho que la pena es un mero mal, o que restringe o priva determinados bienes jurídicos, pues con ello nada se dice acerca de sus fines y objetivos, y nada se dice, por tanto, de lo que esta detrás del Derecho penal. Ello, principalmente, porque castigar o penar sin motivos, establecer y hacer funcionar todo el sistema penal sin objetivos aparentes, más allá del control y dirección social, hoy, en el actual estado de desarrollo de la humanidad, no parece algo aceptable en una sociedad democrática.

Así, la pena, a mi juicio, a la vez que un mal, debe ser un instrumento que, utilizado en forma justa y necesaria, proteja los bienes jurídicos más preciados por la sociedad. ${ }^{9}$

\footnotetext{
${ }^{6}$ Sobre la teoría del fin de la pena y el programa político criminal del Proyecto Alternativo (en adelante, el "PA"), ROXIN, Claus. "Franz von Liszt y la concepción políticocriminal del Proyecto Alternativo" en Problemas básicos del Derecho penal. pp. 37 y ss. Esp. pp. 40-47. Sobre el concepto material de pena, JESCHECK, Tratado de Derecho Penal. Parte General, cit. nota $n^{\circ} 4$, p. 57. Para quien la pena es un juicio de desvalor, público y ético-social, sobre el autor, por la infracción jurídica que cometió culpablemente. Razón por la que ésta siempre tiene un acento negativo y por ello, el carácter de un mal, aunque en último término deba beneficiar al condenado. Para Jeschek, el mal que la pena comporta consiste en la intervención voluntaria en la esfera jurídica del condenado -en su libertad, patrimonio, tiempo libre y estimación socialpues la desaprobación pública se expresa, precisamente, en el hecho de que la pena incida sobre la situación jurídica del culpable. Por ello, negar que la pena tenga el carácter de mal sería tanto como negar el propio concepto de pena. En el mismo sentido, BUSTOS RAMÍREZ, J., HORMAZÁBAL MALARÉE, H., "Pena y Estado", Papers, Revista de Sociología no 13 (1980), pp.97 y ss. Esp. p. 121.

${ }^{7}$ En este sentido, BERDUGO GÓMEZ DE LA TORRE, I.; ZÚÑIGA RODRÍGUEZ, L., (Coord.) Manual de Derecho Penitenciario. Salamanca-Madrid: U. de Salamanca-Colex, 2001, pp. 34 y ss.

${ }^{8}$ Ello, sin perjuicio de que también se tenga presente que, en el caso del PA se trate, para algunos, de revestir a dicho mal de la cualidad de bien o se le muestre como un mal útil o como un mal menor. En este sentido, BAUMANN, Jürgen, y otros, Alternativ Entwurf eines Strafgesetzbucches. Algemeiner Teil. $2^{\mathrm{a}}$ Edic. Tübingen, 1969. p. 29. Cit. por DEMETRIO CRESPO, Eduardo, Prevención general e individualización judicial de la pena, Salamanca: U. de Salamanca, 1999, p. 54.

${ }^{9}$ La concepción de la pena como protección de bienes jurídicos exige que en los casos particulares se imponga aquella pena (según su contenido y extensión) que sea necesaria y, por tanto, que a través de ella resulten protegidos los bienes jurídicos. La pena correcta -es decir, la pena justa- es la pena necesaria. La vinculación total del poder de imponer penas a la idea del fin es el ideal de la Justicia penal. Sólo la pena necesaria es la pena justa. La pena es un medio dirigido a un fin que requiere la adecuación del medio al fin y
} 
Polit. crim. Vol. 4, No 8, (Diciembre 2009), Art. 1, pp. 266-291 (1-26).

[http://www.politicacriminal.cl/Vol_04/n_08/Vol4N8A1.pdf]

Instrumento que sólo se legitima en la medida en que, orientado hacia la consecución de los fines y objetivos aceptados por la comunidad, se fundamenta en una Constitución y un Derecho penal democrático, respetuoso de los Derechos Humanos y de los principios materiales, generado a través de una representación efectiva y veraz de los ciudadanos.

Por otra parte, debe tenerse en cuenta que, a lo largo de la historia del Derecho penal, son múltiples las doctrinas que han intentado dar una respuesta, de acuerdo a su época y sus valores, acerca del fin, el fundamento y los objetivos de la pena. Todas esas respuestas apuntan, sobre todo, a la justificación teórica por la utilización del castigo penal y del mal que éste implica. Esta tarea, obviamente, no ha resultado fácil, por lo que han florecido múltiples teorías que, en menor o mayor medida, y respondiendo a concepciones filosóficas, políticas, ideológicas y religiosas, han intentado resolver dicha problemática y dar sus respuestas a las interrogantes arriba señaladas.

Sin embargo, el punto central de esta problemática jurídico penal sigue siendo, a mi juicio, el hecho de que la pena, en cuanto mal utilizado por el Estado para sancionar las conductas contrarias al ordenamiento penal, sigue aún sin tener una finalidad que fundamente suficientemente su utilización. Sobre todo cuando se entiende que la cuestión del sentido de la pena es diferente de la relativa a su justificación o naturaleza pues se trata del fin que el acto punitivo pueda y deba tener frente al reo o la colectividad. ${ }^{10}$

Felizmente, en los Estados de la Unión Europea se ha mantenido viva la discusión al respecto y se han generado bastantes vueltas a estos temas (tanto en cuanto a la legitimidad o el por qué de la utilización de la pena por parte del Estado, como respecto del para qué) lo que ha implicado que la teleología de la sanción penal, de ese mal causado a los miembros de la sociedad civil, se encuentre en real, profunda y constante revisión, lo que ha permitido, a su vez, sobre todo a partir de la segunda mitad del siglo pasado, un avance cualitativo en los términos de la discusión acerca de los fines y objetivos de la pena. Sin perjuicio de que, en los últimos años, se ha puesto en boga, a propósito de la discusión sobre la expansión y actualización del Derecho penal, una revisión de las teorías retributivas. $^{11}$

Por el contrario, el vacío en la discusión de estos temas se profundiza dramáticamente en aquellos sistemas penales formalistas y decimonónicos, donde aún se presenta la retribución como fundamento del sistema, y donde no se acepta, o simplemente no se produce, la discusión respecto de los conceptos fundamentales del sistema penal. Cuestión que provoca -directa o indirectamente- que aquél se vaya conformando y estructurando

la mayor economía posible en su empleo. VON LISZT, Franz, La idea del fin en el Derecho penal. Programa de la U.de Marburgo, 1882, Granada: Comares, 1995, p. 78.

${ }^{10}$ JESCHECK, Tratado de Derecho Penal. Parte General, cit. nota no 4, p. 57.

${ }_{11}$ Al respecto, SHUNEMANN, Bernd, "Aporías de la teoría de la pena en filosofía. Pensamientos sobre Inmanuel Kant”, InDret Revista para el análisis del Derecho 2 (2008), pp. 2 y ss. FEIJOO SANCHEZ, Bernardo, "Individualización de la pena y teoría de la pena proporcional al hecho. El debate europeo sobre los modelos de determinación de la pena”, InDret Revista para el análisis del Derecho 1 (2007), pp. 2 y ss. 
DURÁN, Mario. “Justificación y legitimación político-criminal de la pena. Concepto, criterios y orientaciones en la actual jurisprudencia nacional".

como un sistema penal autoritario, poco garantista y desconectado de la realidad social del respectivo país. ${ }^{12}$

\section{La necesaria vinculación entre la justificación teórica del castigo penal y su determinación empírica.}

A mi juicio, la perspectiva empírico-valorativa bajo la cual, tradicionalmente, se impone la pena en nuestro Derecho presenta una aridez motivacional, una escasa profundidad de análisis teórico-práctico, que llama profundamente la atención.

En efecto, si partimos de la premisa que la pena no puede traspasar, ni en su gravedad ni en su duración, el grado de culpabilidad ${ }^{13}$ que se irroga a quién ha cometido un hecho considerado como delito, se comprende que uno de los pilares sobre los cuales se funda el ejercicio legitimo del Ius puniendi es, precisamente, la justificación del fin en virtud del cual ha de imponerse la sanción punitiva.

Por ello, la determinación de la medida de una pena, correspondiente a un hecho delictivo concreto, no se satisface sólo con esbozar la subsunción de los hechos al Derecho para que, en definitiva, se posibilite la determinación -meramente numérica- del quantum o intensidad de la sanción. Por el contrario, para que la aplicabilidad práctica de la pena cobre efectivamente un realce garantista en un sistema jurídico de derecho y democrático, creo que habrá de analizar este tema en un terreno mixto o ecléctico, en el que incidan no sólo argumentos relativos a la imputación (objetiva) del hecho típico cometido, sino que, además, tengan injerencia una importante serie de elementos argumentativos, sustentados en reglas y principios político-criminales que guardan directa relación con los fines de la pena. $^{14}$

${ }^{12}$ Al respecto, ZAFFARONI, Eugenio Raúl, (coord.) Sistemas penales y derechos humanos en América Latina. (informe final). Documento final del Programa de investigación desarrollado por el Instituto Interamericano de Derechos Humanos (1982-1986). Depalma. Buenos Aires, 1986. A esta situación contribuyen el propio Estado y la Universidad. El primero a través de una política autoritaria de control social no democrática y la Universidad, con una pobre formación académica - de juristas, futuros jueces y operadores jurídicos- que ignora éstas y otras preocupaciones penales, permitiendo y fomentando la simple repetición de normas del siglo XIX sin que existan un real interés por la investigación y la producción científica, lo que facilita que el estadio de esta discusión, y de otras de igual o mayor importancia, permanezca inmutable. HURTADO POZO, José, La ley importada, Lima: Cedys, 1979; GARCÍA MÉNDEZ, Emilio, Autoritarismo y control social. Argentina-Uruguay-Chile, Buenos Aires: Hammurabi, 1987; ZAFFARONI, Eugenio Raúl, En busca de las penas perdidas. Deslegitimación y dogmática jurídico-penal, Buenos Aires: Ediar, 1989. Esp. pp. 136 y ss. acerca de 'las usinas ideológicas'; FERRAJOLI, Luigi. Derecho y Razón. Teoría del garantismo penal, $4^{\mathrm{a}}$ Edic., Madrid: Trotta, 2000. Esp. 'Los modelos autoritarios'. pp. 40 y ss.

13 Vid. ROXIN, Claus. "Reflexiones Político-Criminales Sobre el Principio de Culpabilidad". En, DEL MISMO, Culpabilidad y Prevención en el Derecho Penal. Trad.: MUÑOZ-CONDE, Francisco, Madrid: Reus S.A., 1981, pp. 46 y ss.

${ }^{14}$ Como expresa el profesor Bustos Ramírez, al tiempo de determinarse judicialmente la pena "se trata de decidir el quantum de la pena según sea la función que se cree que debe perseguir. Por eso, para tal decisión resultan básicos el sentido y el fin de la pena y, además, los momentos en que la filosofía penal del Estado se manifiesta (constitucional, legal, judicial y administrativo de ejecución de la pena)". BUSTOS RAMÍREZ, Juan, Manual de Derecho Penal. Parte General, $3^{\text {a }}$ Edición aumentada, corregida y puesta al día. Barcelona: Ariel, 1989, pp. 394 y ss. 
Polit. crim. Vol. 4, No 8, (Diciembre 2009), Art. 1, pp. 266-291 (1-26).

[http://www.politicacriminal.cl/Vol_04/n_08/Vol4N8A1.pdf]

Esto supone que, al momento de la determinación judicialmente la pena, deben tener vigencia efectiva todos y cada uno de los presupuestos y principios -formales y materialesque inspiran el Porqué y el Para qué de la reacción punitiva. Esto es, una aplicación de la determinación judicial de la pena que considere los principios político-criminales limitadores del Ius Puniendo Estatal. ${ }^{15}$

Por lo mismo, si se reduce la sustentabilidad y legitimidad de la intervención penal, sólo a los aspectos relacionados con la teoría del delito, ${ }^{16}$ se estaría posibilitando el encubrimiento de uno de los efectos de carácter penal, más trascendentales sobre los cuales se sustenta la existencia misma del sistema: Ser una garantía.

Por ello, a mi juicio, debe quedar absolutamente asumido que los distintos criterios de determinación práctica de la pena, aplicables fácticamente a cada caso in concreto, dependen siempre de cuál sea el concepto y el fin de la pena desde el que se parte. Es más, depende el propio análisis del delito del que se parte. Ello, como señala Zaffaroni porque

"la pena es la consecuencia del delito y, necesariamente, debe el delito reflejarse en su determinación. Delito y pena no pueden ser conceptos separados en forma tal que nada diga el uno acerca del otro, puesto que uno es antecedente necesario de la otra, y ésta, a su vez, la consecuencia natural de la anterior. Todo corte arbitrario, toda solución de continuidad que los desvincule, no es otra cosa que la confesión de un fracaso sistemático". ${ }^{17}$

Así, en este sentido, indispensable es que la dogmática penal contemporánea, en vez de rehuir la vinculación lógica existente entre la praxis judicial y los fines de la pena, establezca un análisis marco, en donde se reduzca y se controle el eventual halo de

\footnotetext{
${ }^{15}$ En este sentido, se señala que "cuando se decide cuánto castigo a de padecer el reo, es el momento en el que las cuestiones fundamentales sobre el por qué y para qué se le sanciona, han de descender de lo programático a la sentencia concreta. QUINTERO OLIVARES, Gonzalo, "Determinación de la Pena y Política criminal", $C P C, \mathrm{n}^{\circ} 4$ (1982) pp. 49 y ss. Esp. p. 52; QUINTERO OLIVARES, Gonzalo, "Política criminal y determinación de la pena", en Doctrina Penal, Buenos Aires: 1982.

${ }^{16}$ Adhieren a esta postura, entre otros, Silva Sánchez, quién señala: "No puede dudarse que de que el juez hace política criminal; de modo especial en la individualización de la pena, donde en principio dispone de más libertad. Pero debería huirse a la tentación de pensar que ésta ha de ser una política criminal directa, esto es, en la que se consideraran de modo inmediato los fines del Derecho penal. Precisamente en un contexto así, para evitar el intuicionismo, el puro decisionismo o, sin más, la arbitrariedad, es preciso que la política criminal se canalice por vías dogmaticas. Esto es, que, en la medida de lo posible se traduzca en reglas y no se quede en el plano de los principios. Por lo tanto (...), la teoría de la determinación de la pena debe manifestarse, ante todo, como la dimensión cuantitativa (o de grado) de un sistema de la teoría del delito (...). SILVA SANCHEZ, Jesús María, "La Teoría de la Determinación de la Pena Como Sistema (Dogmático): Un Primer Esbozo". InDret, No 2 (2007). Barcelona: pp. 4-5.

${ }^{17}$ ZAFFARONI, Raúl Eugenio, Tratado de Derecho Penal. Parte General, Tomo V, Buenos Aires: Ediar Editores, 1988, p. 281.
} 
DURÁN, Mario. “Justificación y legitimación político-criminal de la pena. Concepto, criterios y orientaciones en la actual jurisprudencia nacional".

discrecionalidad al cual puede arribar el juez, en el afán de buscar la verdad procesal en su vinculación con los fines de la pena. ${ }^{18}$

\section{Criterios de determinación judicial de la pena y justificación teórica del castigo penal.}

Aceptada la línea de trabajo aquí trazada, esto es, que el punto de partida de la individualización judicial de la pena ${ }^{19}$ es la determinación de los fines de la pena, se hace necesario establecer criterios en virtud de los cuales los operadores del sistema judicial puedan justificar -racionalmente- la aplicación de la pena al caso concreto.

Así, sobre la base de fines político-criminales claramente definidos, cabe pronunciarse sobre qué hechos son de importancia para la individualización de la pena en el caso concreto y como éstos deben valorarse si hubiera lugar a ello. ${ }^{20}$ En este sentido, la dogmática penal, intentando dar una consistencia tuteladora a la referida individualización, ha trazado una serie de criterios que permiten delimitar la orientación que ha de asumir la pena en su exteriorización hacía la realidad particular.

Para ello, desde los tradicionales razonamientos retributivos y preventivos, tanto generales como especiales, la dogmática tradicional ha creado, entre otros, tres criterios fundamentales para la aplicación de la pena en el caso concreto; la teoría de la pena exacta, la teoría del ámbito del juego y la teoría del valor posicional.

La llamada teoría de la pena exacta o puntual -Punktstrafe- principalmente se basa en la idea de que el juez, al tiempo de imponer la sanción, debe ceñirse rigurosamente a la culpabilidad del sujeto, sin atender a otros fines que no sean los retributivos, pues, se debe compensar y/o expiar el mal que se causó. ${ }^{21}$ De lo que se trata -como se observa- es que a la culpabilidad sólo le puede corresponder una pena exactamente determinada - punktuell-. ${ }^{22}$

La denominada teoría del ámbito de juego o del margen de libertad -Spielraumtheorieseñala que no se puede propender a que la pena se ajuste íntegramente a un criterio puntual y exacto de culpabilidad, ya que ello sería inverosímil. De lo que se trata, es que la pena, ajustada a la culpabilidad, comprenda un marco determinado entre un mínimo y un máximo, no siendo una magnitud precisa, sino, un margen de libertad adscrito al juez, en donde primero se ha de determinar la culpabilidad del individuo para, posteriormente, a propósito del juego entre lo mínimo y lo máximo, aplicar criterios de prevención especial como de prevención general, o sólo los primeros.

\footnotetext{
${ }^{18}$ Sobre el problema de la determinación judicial de la pena y la discrecionalidad, Vid. FERRAJOLI, Luigi, Derecho y Razón. Teoría del Garantismo Penal, Madrid: Trotta S.A.,1995, pp. 402 y ss.

19 En el Derecho comparado, para identificar la individualización judicial de pena, se emplean las expresiones: "Strafzumessung" (Alemania), "Sentencing" (Inglaterra), "Traiment" (Francia).

${ }^{20}$ Al respecto, JESCHECK, Hans-Heinrich, Tratado de Derecho Penal. Parte General, no 4, pp. 790 y ss.

${ }^{21}$ MAGARIÑOS, Mario, "Hacia un Criterio Para la Determinación Judicial de la Pena". En, AA.VV., Determinación Judicial de la Pena, Buenos Aires: Editores del Puerto, 1993, pp. 74 y ss.

${ }^{22}$ ROXIN, Claus, "La Determinación de la Pena a la Luz de la Teoría de los fines de la Pena". En, ROXIN, Culpabilidad y Prevención en el Derecho Penal, cit. nota ${ }^{\circ} 13$, pp. 46 y ss.
} 
Polit. crim. Vol. 4, No 8, (Diciembre 2009), Art. 1, pp. 266-291 (1-26).

[http://www.politicacriminal.cl/Vol_04/n_08/Vol4N8A1.pdf]

Dicho en otros términos,

"la pena no se encuentra justificada sólo como respuesta justa frente al ilícito culpable; si bien debe compensar la culpabilidad -en el sentido que no puede sobrepasarla-, no tiene solamente esta finalidad -a diferencia de lo que sostienen las teorías absolutas- o la de posibilitar la expiación -a través de la aceptación y elaboración del mal-. Además, la pena debe cumplir, al mismo tiempo, funciones de prevención". ${ }^{23}$

Por último, la teoría del valor posicional o del valor de empleo -Stellungs werttheorieestablece, a objeto de superar las antinomias fácticas existentes entre los fines retributivos y preventivos de la pena, que en su aplicación, se ha de de asignar un valor de empleo al fin que se desea buscar con la pena. Así, sólo la culpabilidad debe ser tomada en consideración para fijar la magnitud de la pena. La prevención, en tanto, ha de tenerse en cuenta para todas las restantes decisiones en el marco de la individualización de la pena. ${ }^{24}$

Retribución de la culpabilidad y prevención aparecen aquí, por tanto, como grados sucesivos e independientes de la determinación de la pena. ${ }^{25}$

\section{Justificación y legitimación de la pena en Chile, perspectivas en la actual jurisprudencia.}

Para comenzar, es necesario establecer que, por razones histórico-culturales, ${ }^{26}$ tanto el sistema de sanciones, como la determinación judicial de la pena existentes en nuestro sistema, poseen una clara orientación hacia las teorías absolutas de la pena. ${ }^{27}$

En efecto, si partimos de la base que al momento de redactarse nuestro Código Penal la comisión designada para tal cometido ${ }^{28}$ siguió de cerca las ideas del profesor Español

${ }^{23}$ ZIFFER, Patricia, "Consideraciones Acerca de la Problemática de la Individualización de la Pena". En, AA.VV., Determinación Judicial de la Pena, Buenos Aires: Editores del Puerto, 1993, p. 91.

${ }^{24}$ Vid. JESCHECK, Tratado de Derecho Penal, cit. nota ${ }^{\circ} 4$, p. 795.

${ }^{25}$ Sobre el origen y critica de la referida postura, Vid. ROXIN, Claus, "Prevención y Determinación de la Pena". En, ROXIN, Culpabilidad y Prevención en el Derecho Penal, cit. nota n 13, pp. 117 y ss.

${ }^{26}$ Es sabido, que el código penal chileno se inscribe en el periodo llamado "de creación de Derecho penal liberal", que se orienta entre los códigos napoleónico de 1810, bávaro de 1813 y el italiano de 1889, resultado ser un código racionalista, clásico, individualista, igualitario, humanitario y liberal, cuya base de inspiración está constituida, principalmente, por el código hispano de 1848, en su versión de 1850 y por el código belga de 1867. Sobre el particular, Vid. RIVACOBA Y RIVACOBA, Manuel, Evolución histórica del Derecho penal chileno, Valparaíso: Edeval, 1991, pp. 59 y ss.

${ }^{27}$ Para un análisis crítico del CP Chileno, BARBERO SANTOS, Marino, "La fundamentación doctrinal y la orientación político-criminal del Código Penal Chileno en el panorama actual del Derecho Penal" en Actas de las Jornadas Internacionales en celebración del centenario del Código Penal Chileno, Valparaíso: Edeval, 1975 , pp.35 y ss.

28 Dicha comisión, inició sus sesiones el 8 de marzo de 1870 y terminó sus trabajos el 22 de octubre de 1873 , estando conformada por los juristas, Alejandro Reyes (quien la presidió), Eulogio Altamirano, José Clemente Fabres, José Antonio Gandarillas, José Vicente Abalos, Diego Anstrong y Manuel Rengifo. Durante el curso 
DURÁN, Mario. “Justificación y legitimación político-criminal de la pena. Concepto, criterios y orientaciones en la actual jurisprudencia nacional".

Joaquín Francisco Pacheco (1808-1865), ${ }^{29}$ comprenderemos que la teoría que primó en aquel entonces -sobre el fin de la pena- era, precisamente, la retributiva.

Así, para Pacheco, quién adhería a los postulados de la denominada Escuela Clásica,

"los seres morales, inteligentes y libres, conociendo la regla que les está impuesta, gozan de la libertad para seguirla o quebrantarla (...), cuando la infringen y faltan a ella, es necesario que venga enseguida el restablecimiento del orden que se quebrantó, la reparación del punto trastornado. Es pues, la regla del orden moral que se reforme y enmiende en él el mal que se causa, que se vuelva a soldar y afirmar el anillo por donde fue rota la cadena. Y la idea que sigue a esta naturalmente, la que la explica y completa, no es otra que la idea del sufrimiento, la idea de expiación, la idea de mal por mal, la idea de castigo". 30

Más aún, profundizando al argumento de considerar la retribución como la base del castigo en nuestro Código Penal, aparece la figura de Don Robustiano Vera, quién, además de servir como secretario a la comisión redactora del código, señalaba:

"la justicia penal existe porque ella es (...) un elemento necesario para (la) conservación (de la sociedad)", que debería armonizarse con la teoría iusnaturalista de la justicia, porque "la lei penal no puede estar jamás en oposición con ella i lejos de eso, allí debe estar su limite i dentro de ella su circulo de acción armonizado en cuanto sea posible con los intereses de la sociedad en que hace sentir sus efectos". ${ }^{31}$

Es más, dicho comentarista, explicando el artículo $69^{32}$ del Código Penal vigente, señalaba:

"Este articulo (...) tiene por base la más exacta proporcionalidad entre la pena y el delito, mirando, sin embargo, a la mayor o menor extensión del mal que ha producido. En jeneral, este artículo prohíbe imponer pena mayor que la señalada por la lei al delito, i advierte que cuando mas el juez solo puede avanzar hasta el grado máximo que ella le señala, (...) El juez es solo para aplicar la pena: no es legislador para

de su desempeño, el señor Abalos fue reemplazado por Adolfo Ibañez. Siendo secretarios, sucesivamente, Julio Prieto Urriola, Robustino Vera y Osvaldo Rengifo.

${ }^{29}$ Es de tal preponderancia la figura de Pacheco en la elaboración de nuestro código, que se llega a señalar que la comisión redactora del código penal chileno, tomó como piedra angular el código penal español de 1848, precisamente, porque contaban con un comentario (El código penal concordado i comentado, Madrid, $1856,2^{\mathrm{a}}$ edición) escrito por el propio Pacheco. Para una mejor comprensión de los aportes del citado autor en relación al código español de 1848, Vid. ANTON ONECA, José. "El código penal de 1848 y D. Joaquín Francisco Pacheco". ADPCP, Tomo XVIII. Fascículo III. Madrid: MCMLXV., pp. 473 y ss.

${ }^{30}$ PACHECO, Joaquín Francisco, Estudios de Derecho Penal. Lecciones pronunciadas en el Ateneo de Madrid, Tomo primero, Madrid: Boix Editor, 1842, pp. 81-82.

31 Apud. MATUS ACUÑA, Jean Pierre, "Fernández, Fuenzalida y Vera: Comentaristas, autodidactas y olvidados. Análisis diacrónico y sincrónico de la doctrina penal chilena del siglo XIX". Ius et Praxis, Vol. 12, $\mathrm{N}^{\circ} 1$ (2006), pp. 31-67. ISSN 0718-0012.

${ }^{32}$ El referido articulo 69 de nuestro código, permaneciendo incólume desde el año 1874 a la fecha, y, siendo una copia textual del inciso final del artículo 74 del código penal español de 1850, señala: "Dentro de los limites de cada grado el tribunal determinará la cuantía de la pena en atención al número y entidad de las circunstancias atenuantes y agravantes y a la mayor o menor extensión del mal producido por el delito". 
Polit. crim. Vol. 4, No 8, (Diciembre 2009), Art. 1, pp. 266-291 (1-26).

[http://www.politicacriminal.cl/Vol_04/n_08/Vol4N8A1.pdf]

establecerla en cada caso i, buena o mala, su deber es aplicarla como se ha sancionado". 33

Por estas razones, es claro que nuestro código penal, de factura clásica e inspirado en una ideología de corte liberal, obedece al propósito de establecer un mecanismo de determinación de penas lo más rígido posible a fin de restringir al máximo el arbitrio judicial. $^{34}$

Ello tiene como efecto directo el grave hecho de que los márgenes concedidos al juez para adecuar la reacción punitiva a la culpabilidad del sujeto son sumamente estrechos, transformándose la labor del Iudex -en la práctica-, en una mera aplicación matemática de las formulas que han de rodear la sanción punitiva. ${ }^{35}$ Pues, dicho en otros términos, al consagrarse y establecerse la sanción de cada delito en relación a la intensidad de su injusto que, en definitiva, depende de la valoración de la acción y de la lesión al bien jurídico comprometido, se posibilita que dentro ese marco penal, el tribunal regule la pena conforme a la reprochabilidad personal del agente (culpabilidad). ${ }^{36}$

\subsection{Manifestación de la idea predominantemente retributiva de la pena en la jurisprudencia.}

Al analizar jurisprudencia reciente, se puede afirmar que la idea de retribución jurídica, presentada bajo conceptos tales como "castigo proporcional", "razones de justicia", "pena proporcionalmente retributiva al ilícito cometido" y/o "sanción condigna al hecho reprobado", son sólo algunas de las expresiones de las que se han valido nuestros tribunales superiores de justicia para manifestar el carácter compensatorio y expiativo de la sanción penal.

Dicho postulado, de manera resumida, queda expuesto en un fallo de la Ilustrísima Corte de Apelaciones de Santiago, el cual expone que al tiempo de individualizarse la sanción,

\footnotetext{
${ }^{33}$ VERA, Robustiano, Código Penal de la República de Chile Comentado. Santiago: Imprenta de P. CADOT I Ca., 1883, pp. 236-237.

${ }^{34}$ En ese contexto la propia jurisprudencia ha dicho "Que en cuanto a la determinación de la pena, en relación con los principios de tipicidad, objetividad e igualdad que se han expuesto precedentemente, y no de subjetividad, conviene tener presente (...) la opinión del profesor Novoa que establece (...) "que la determinación de la pena aplicable a un determinado delincuente se transforma en un calculo regido por normas legales obligatorias (...) y del profesor Etcheberry que señala como característica del sistema chileno la de ser un "sistema rígido de determinación de penas con una serie de reglas minuciosas que convierte la aplicación de las penas en una operación casi mecánica" (...)". Corte Suprema de Justicia. Fallo Causa Rol No 1876- 01, de 5 de junio de 2002. Gaceta Jurídica No 264, Junio (2002), p. 164.

${ }^{35}$ CURY URZUA, Enrique, Derecho Penal. Parte General. Tomo II. Segunda Edición Actualizada, Santiago: Editorial Jurídica de Chile, 1992, pp. 315 y ss. ETCHEBERRY, Alfredo, Derecho Penal. Parte General. Tomo Segundo. Tercera Edición Revisada y Actualizada, Santiago: Editorial Jurídica de Chile, 1998, pp. 137, 170, 171.

${ }^{36}$ GARIDO MONTT, Mario, Derecho Penal. Parte General. Tomo I, Santiago: Editorial Jurídica de Chile, 1997, p. 256. POLITOFF, Sergio, "Fines de la Pena y Racionalidad en su Imposición", Ius Et Praxis, año 4, № 2 (1998), Facultad de Ciencias Jurídicas y Sociales de la Universidad de Talca, pp. 9-16.
} 
DURÁN, Mario. “Justificación y legitimación político-criminal de la pena. Concepto, criterios y orientaciones en la actual jurisprudencia nacional".

"se da origen a la graduación y proporcionalidad de la pena, que en concepto de Mezger es la medida del injusto y de la culpabilidad, (...) desarrollándose la exigencia perentoria de proporcionalidad entre la conducta delictiva y la pena asignada por la ley, puesto que (...), la pena tiene por fundamento restablecer el equilibrio de un ordenamiento jurídico armonioso, alterado gravemente por la perpetración de un delito, de este modo (...), delito y pena son factores estrechamente relacionados entre sí y que deben guardar entre ellos una proporción que tienda a su equivalencia (...)".37

Como puede observase, el modelo compensatorio de mal por mal, negación por negación o de la negación de la negación del Derecho -que inspira la retribución penal-, en este caso, se evidencia como una restauración por equivalencia del orden jurídico quebrantado frente a la conducta considerada como delictuosa. De tal forma, lo único preponderante, según el fallo antes descrito, es que al tiempo de aplicarse la pena, ésta, en cuanto mal, sea proporcional al hecho delictivo cometido. ${ }^{38}$

En el mismo sentido, la Excelentísima Corte Suprema de Justicia, haciendo eco de la institución del debido proceso -consignado en el artículo $19 \mathrm{~N}^{\mathrm{o}} 3$ inciso $5^{\circ}$ de la Constitución- ha señalado que, en la individualidad de la pena, se requiere la formulación de una sentencia informada con los resguardos que impidan errores y abusos y, en la perspectiva que nos ocupa,

"la aplicación de una sanción condigna y proporcionalmente retributiva al hecho reprochado en armonía con el sistema jurídico todo, especialmente punitivo, de tal forma que no se produzcan odiosas y perjudiciales discriminaciones y resultados exagerados e inaceptables (...), las más de las veces ocasionados por desconocerse precisamente las garantías y derechos que el propio ordenamiento jurídico ha ido incorporando con el avance de la civilización, en resguardo del individuo en su relación con el Estado". ${ }^{39}$

Así, en el contexto del presente fallo de la Corte Suprema, se podría inferir que la retribución, en cuanto fin inspirador de la reacción punitiva, constituiría uno de los frenos y contrapesos que delimitarían el ámbito valido de acción adscrito al sentenciador en la determinación judicial de la pena, pues, en la medida en que "se determine una pena proporcionalmente retributiva al hecho cometido" a través de un justo y racional

\footnotetext{
${ }^{37}$ Corte de Apelaciones de Santiago, Fallo Causa Rol No 64.809-2001, de 26 de octubre de 2001. De manera idéntica, Vid. fallo del mismo tribunal, de 11 de abril de 2003. Gaceta Jurídica No 274, Abril (2003), pp. 222 y ss.

${ }^{38}$ En este sentido, es dable dejar en claro que la postura de Mezger -a quien se cita en la fallo en comento-, en relación a lo que él llama "graduación judicial de la pena" es que en la aplicación práctica de ésta, se deben tomar en cuenta tan sólo, por un lado, el grado de lesión del derecho y, por el otro, el de la culpabilidad -tanto culpabilidad por el hecho en sentido estricto, como la culpabilidad por la conducta del autor-. En tal supuesto, según dicho autor, la pena no puede jamás abandonar el criterio de la retribución, puesto que los fines preventivos generales y preventivos especiales, deben cumplir tan sólo una función accesoria a la pena. MEZGER, Edmund, Derecho Penal, Libro de Estudio, Parte General, Buenos Aires: Bibliográfica Argentina, 1958, pp. 383 y ss. Para indagar acerca de la implicancias del concepto de culpabilidad asumido por Mezger, Vid. MUÑOZ CONDE, Francisco, Edmund Mezger y el Derecho Penal de su Tiempo. Estudios Sobre el Derecho Penal en el Nacionalsocialismo, Valencia: Tirant Lo Blanch, 2003, pp. 51 y ss.

${ }^{39}$ Corte Suprema. Fallo Causa Rol No 2430-2005, de 19 de octubre de 2005.
} 
Polit. crim. Vol. 4, No 8, (Diciembre 2009), Art. 1, pp. 266-291 (1-26).

[http://www.politicacriminal.cl/Vol_04/n_08/Vol4N8A1.pdf]

procedimiento, se resaltaría el principio de igualdad-contenido en el artículo $19 \mathrm{n}^{\mathrm{o}} 2$ de la Constitución- evitándose, en consecuencia, errores y abusos producto de perjudiciales discriminaciones. La retribución, en ese sentido, en consonancia con el principio de igualdad, se transformaría en una verdadera garantía. ${ }^{40}$

En este último sentido, el máximo tribunal ha fallado que

"el principio de igualdad en la determinación objetiva de la responsabilidad penal, conforme al cual la sanción debe ser el resultado de la determinación de criterios generales, evitando distorsiones y tratamientos discriminatorios e injustificados para diversos sujetos en igualdad de condiciones (...), ha de determinar la necesidad de un castigo proporcional y condigno con los hechos". ${ }^{41}$

De este modo, es posible comprender -en términos generales- que la proporcionalidad en la que se funda la aplicación de una pena en nuestro Derecho, según el criterio esbozado por nuestros sentenciadores, ha de ser en base a un equilibrio aceptable de igualdad legal, que debe responder a una interconexión entre los presupuestos de la reacción punitiva y la reacción misma, ${ }^{42}$ pues, "la aplicación igualitaria de la ley, que conduce necesariamente a que la ley penal y especialmente, la sanción, se aplique en un marco de igualdad y

\footnotetext{
${ }^{40}$ Políticamente, en su significación liberal, la teoría absoluta de la pena en virtud de las exigencias de una pena proporcionada a la gravedad del hecho y a la culpabilidad del autor, de un mal adecuado al mal del delito, significa una garantía del ciudadano frente a un eventual abuso por el Estado. Filosóficamente, el humanismo al que responde, es aquel que tiene por misión elevar y tutelar la dignidad del hombre y prohibir su instrumentalización en aras de fines utilitarios. En este sentido, Vid. MIR PUIG, Santiago, Introducción a las Bases del Derecho Penal. Buenos Aires: B de F, 2003, pp. 49 y ss. GARCIA PABLOS DE MOLINA, Antonio, Introducción al Derecho Penal. Cuarta edición, Madrid: Editorial Universitaria Ramón Areces, 2006, pp. 249 y ss.

${ }^{41}$ Corte Suprema. Fallo Causa Rol No 5019-2006, de 20 de diciembre de 2006.

${ }^{42}$ En tal sentido, el Tribunal de Juicio Oral de Punta Arenas, citando a los autores españoles Manuel Cobo del Rosal y Tomás Vives Antón -Derecho Penal. Parte General, p. 88- manifestó: "la exigencia de proporcionalidad ha de determinarse mediante un juicio de ponderación entre la carga coactiva de la pena y el fin perseguido por la conminación penal. La ponderación ha de efectuarse desde la perspectiva del derecho fundamental y del bien jurídico que ha venido a limitar su ejercicio, determinando si las medidas adoptadas son o no proporcionadas a la defensa del bien que da origen a la restricción. Es evidente que la proporcionalidad así entendida, dada la función de tutela del orden jurídico que a la pena corresponde, ha de atender, en primer término, a la gravedad del delito cometido, esto es, al contenido del injusto, al mal causado y a la mayor o menor reprochabilidad del autor. La pena proporcionada a la gravedad del delito será también, en abstracto, la adecuada a la finalidad de tutela. Mas pudiera suceder que, en el caso concreto, dicha finalidad quedara satisfecha con una pena menor e, incluso, sin pena alguna. En tal caso la proporcionalidad habría de ser entendida conforme a los requerimientos de la finalidad de tutela, que es el auténtico objeto de la ponderación, y no según la gravedad del delito, que es sólo un criterio genérico para efectuarla. En este sentido vendría a confluir con la necesidad". Tribunal de Juicio Oral en lo Penal de Punta Arenas. Fallo Causa RIT N³7-2007, RUC 0600699450-2, de fecha 25 de julio de 2007.
} 
DURÁN, Mario. “Justificación y legitimación político-criminal de la pena. Concepto, criterios y orientaciones en la actual jurisprudencia nacional".

proporcionalidad, permite que lo fundamental sea la determinación de la pena con criterios objetivos y no subjetivos". 43

A mayor abundamiento, para la excelentísima Corte Suprema, es de tal magnitud la ponderación judicial del injusto en base a reglas y directrices de igualdad legal que "los principios de mínima intervención y de lesividad, que dicen relación, el uno con la proporcionalidad de la pena en relación con la gravedad del hecho; y el otro, por el cual sólo se deben perseguir hechos que afecten un bien jurídico, no son más que consecuencia del principio de igualdad ante la ley penal". 44

Sin embargo, no debe creerse que la idea de retribución jurídica sustentada por nuestra judicatura se agota en el principio de igualdad ante la ley penal. Muy por el contrario, la idea matriz de la sanción penal a aplicar retributivamente, ha sido armonizada con el principio de culpabilidad, retratado -según nuestros tribunales- en el artículo $19 \mathrm{~N}^{\circ} 3$, inciso $6^{\circ}$ de la Constitución Política de la República, pues, como se ha señalado,

"no hay pena sin culpabilidad, esto es, sólo la culpabilidad comprobada -y su contenido volitivo- por los medios de prueba legal, justifican la valoración o juicio de reproche (...) de tal forma que la pena no debe rebasar la medida de la culpabilidad (autor español José Cerezo Mir: El delito como acción culpable), o sea que la sanción penal no debe ser desproporcionada o exceder arbitrariamente el disvalor objetivo que contiene la conducta del agente". ${ }^{45}$

En tal sentido, la idea de retribución, aparecería como un elemento fundamentador y legitimador, que mediaría entre la aplicación de una pena proporcional y el juicio de reproche irrogado al autor del ilícito. De esta manera, comprendiendo a la culpabilidad como reprochabilidad de la voluntad, en orden a considerar que existe reproche cuando el autor, en su situación libre, hubiera podido actuar de otra forma y no lo hizo, nos evidencia que la adecuación entre la pena y la culpabilidad -según nuestra jurisprudencia- ha de perseguir una concepción retributiva de la pena. ${ }^{46}$ Ello, dicho en otros términos, implica que el esquema "culpabilidad - reproche - pena" en cual se agota la retribución justa de la

${ }^{43}$ Corte Suprema. Fallo Causa Rol No 1876- 2001, de 5 de junio de 2002. Gaceta Jurídica $\mathrm{N}^{\circ}$ 264, Junio (2002), pp. 164 y ss.

${ }^{44}$ Corte Suprema. Fallo Causa Rol No 5688-2003, de 24 de febrero de 2004.

${ }^{45}$ Corte de Apelaciones de San Miguel. Fallo Causa Rol N ${ }^{\circ} 1200-2003$, de 24 de septiembre de 2003. De manera idéntica Vid. Del mismo Tribunal. Fallo Causa Rol N 3361-2003, de 12 de mayo de 2004. Gaceta Jurídica $\mathrm{N}^{\mathrm{o}} 289$ (2004), p. 183 y ss.

${ }^{46}$ Sin embargo, como expresa Mercedes García Aran, "el modo en que el concepto normativo de culpabilidad legitima el Derecho penal, posiblemente se diferencia de otras teorizaciones posteriores, en su falta de referencia a la función del Derecho penal en el marco de la actividad estatal de regulación de conductas. Debe imponerse la pena, porque el autor concreto ha manifestado una actitud jurídicamente desaprobada cuando podía, en sus circunstancias, haber hecho lo contrario. Y el Estado tiene derecho a exigirle que cumpla las normas. Los polos enfrentados en la relación son «individuo frente a la norma» y «Estado frente al individuo» (...) simplificando mucho el mecanismo legitimador, éste es casi tautológico: debe castigarse a los culpables (es decir, a los que han actuado libremente), porque han actuado libremente (es decir, porque son culpables). Con lo cual, si la culpabilidad ha de servir para justificar la intervención penal ésta queda débilmente justificada. GARCÍA ARÁN, Mercedes, "Culpabilidad, legitimidad y proceso" ADPCP, Tomo XLI, Fascículo I (1998), p. 79. 


\section{Polít. crim. Vol. 4, № 8, (Diciembre 2009), Art. 1, pp. 266-291 (1-26). [http://www.politicacriminal.cl/Vol_04/n_08/Vol4N8A1.pdf]}

culpabilidad, se asienta, a la luz de los fallos analizados, en la medida adecuada que posibilita la legitimación igualitaria del reproche en la aplicación y determinación de la pena. ${ }^{47}$

En este sentido, la Ilustrísima Corte de Apelaciones de San Miguel, ha señalado el elemento angular que inspira a la culpabilidad en nuestro Derecho ya que,

"según la opinión dominante en nuestro país, la culpabilidad se identifica con el reproche que se formula al autor de una conducta típica y antijurídica por haberla realizado teniendo a su alcance la real posibilidad de haber actuado de manera distinta (...) Que, siendo el problema esencial de la culpabilidad establecer cuáles son las condiciones que determinan que a un individuo corresponde imponerle castigo penal por su acto típico y antijurídico (...), para el establecimiento de la culpabilidad penal, reprochabilidad o su ausencia, son esencialmente gravitantes todas las circunstancias concomitantes- bajo las cuales se encontraba el hechor en el momento crítico (Reinhard Frank) (...) Que, sin perjuicio de las discrepancias doctrinarias sobre el concepto de culpabilidad, su estructura y, sobre todo, su función en la fundamentación y medición de la pena, existe un cierto acuerdo para considerar como elemento esencial para el juicio de reproche, la exigibilidad al sujeto imputable de una conducta distinta conforme a Derecho, que algunos denominan motivación normal. Así, la exigencia de otra conducta significa como elemento integrante de la base del juicio de culpabilidad, la posibilidad de exigir al autor de una conducta típica y antijurídica, que en las concretas circunstancias de su situación conflictiva se hubiera motivado conforme a las exigencias de Derecho; en otras palabras, tener la certeza de que en vez de decidirse autónomamente a actuar contra Derecho, el sujeto hubiera estado en condiciones de dirigir libremente su conducta hacia el acatamiento de las normas, esto es, hacia el respeto por la integridad del respectivo bien jurídico amparado (...) Que, el principio no hay pena sin culpabilidad cuenta entre los postulados fundamentales de la doctrina jurídico penal tradicional y es considerado un imprescindible instrumento de la justicia (Jiménez de Asúa, Tratado de Derecho penal, T. V, pág. 38; Mir Puig, Sobre el principio de culpabilidad como limite de la pena, en El Poder Penal del estado, Homenaje a Hilde Kaufmann, 1985, pág. 365 y ss) (...) Que, en la doctrina imperante en nuestro medio reconoce al principio de culpabilidad como un pilar fundamental del derecho Penal Moderno, postulado básico, conforme al cual, sólo debe ser castigado

\footnotetext{
${ }^{47}$ Al respecto, un fallo emanado del Tribunal de Juicio Oral en lo Penal de Puerto Montt señala, "Que entre las garantías que se enuncian, más halla de los principios de reserva o legalidad, tipicidad, irretroactividad, reglamentación objetiva de la sanción e inocencia, se debe respetar el principio de culpabilidad y el de determinación normativa que se viene indicando, principios en los que se contiene, por cierto, los de graduación y proporcionalidad de la pena. Adecuando lo anterior a palabras de Novoa, se expresaría: "Que la pena tenga por fundamento restablecer el equilibrio de un ordenamiento jurídico armonioso, alterado gravemente por la perpetración de un delito, se sigue que delito y pena son factores estrechamente relacionados entre sí y que deben guardar entre ellos una proporción que tienda a su equivalencia" (...) De cierto es que el legislador a propósito de sancionar el actuar del agente en un delito determinado, viene respetando los principios que se han referido, estableciendo a la sazón, los aspectos generales de los ilícitos penales, como son grados de desarrollo del delito, grados de participación, circunstancias modificatorias de responsabilidad, grados de representación del reproche del actuar y su extensión, pero todos vinculados a la culpabilidad del caso concreto". Tribunal de Juicio Oral en lo Penal de Puerto Montt. Fallo Causa RIT N ${ }^{\circ} 9$ 2006, RUC 0600461991-7, de fecha 5 de diciembre de 2006.
} 


\section{DURÁN, Mario. “Justificación y legitimación político-criminal de la pena. Concepto, criterios y orientaciones en la actual jurisprudencia nacional".}

con una pena criminal el autor de una conducta típica y antijurídica cuando ésta le pueda ser personalmente reprochada; solamente en este caso es culpable (...)". ${ }^{48}$

Más aún, desde esta perspectiva, y en términos de Manuel De Rivacoba,

"se ha de reconocer que la pena sigue como consecuencia jurídica, una vez que se ha comprobado la existencia, asimismo, de otros requisitos que exige igualmente el concepto de delito, a la formulación de una reprobación objetiva y un reproche personal, es decir, expresa la concreción de una desvaloración, lo cual es la quintaesencia de la retribución". 49

Por todo ello, se puede asumir que nuestros tribunales, ciñéndose a un criterio normativo de culpabilidad, ${ }^{50}$ establecen sobre el denominado reproche el peso de la justificación y limitación del castigo, en consonancia con la exigibilidad de conducta adecuada a la norma, la imputabilidad y el conocimiento de la antijuridicidad. ${ }^{51}$

Ahora bien, de acuerdo a los fallos citados, la medición de la pena se sujeta a la medida de la culpabilidad y, por lo mismo, la judicatura entiende que la exigibilidad de otra conducta, basada en la libertad o libre albedrío, aportaría el plus necesario para considerar que a los ciudadanos, en cuanto seres libres, les es exigible el cumplimiento de las normas. Si no las

${ }^{48}$ Corte de Apelaciones de San Miguel. Fallo Causa Rol N 2608- 2000, de 27 de Junio de 2001. Sobre el razonamiento último del fallo recién transcrito, Vid. Del mismo Tribunal. Fallo Causa Rol N ${ }^{\circ} 2776$, de 25 de agosto de 1989. Gaceta Jurídica No 111 (1989), p. 75.

${ }^{49}$ DE RIVACOBA Y RIVACOBA, Manuel, Función y Aplicación de la Pena, Buenos Aires: Ediciones Desalma, 1993, p. 48.

${ }^{50}$ Se estima por la mayoría de doctrina que fue con Frank y -posteriormente- Goldschmidt en donde se consolidó la estructura normativa de culpabilidad pues, frente a la imposibilidad de los criterios de vinculación psicológica de demostrar la culpa inconsciente y su inoperancia para la cuantificación de la pena, surge la culpabilidad como juicio reproche al autor por haber cometido el delito. Al respecto Vid. FRANK, Reinhard, Sobre la Estructura del Concepto de Culpabilidad, Buenos Aires: B de F, 2002. [Titulo Original en alemán: "Über den aufbau des Schuldbegriffs", Giessen, 1907]. GOLDSCHMIDT, James, La Concepción Normativa de la Culpabilidad. Trad.: DE GOLDSCHMIDT, Margarethe; NUÑEZ, Ricardo, $2^{\circ}$ Ed., Buenos Aires: B de F, 2002. [Titulo original en alemán: "Normativer Schuldbegriff", Berlín, 1930]. MEZGER, Derecho Penal, cit. nota n 38 , pp. 189 y ss.

${ }^{51}$ Es dable precisar, que la visión normativa de culpabilidad sobre la que se basa la reprochabilidad personal de la acción típica y antijurídica, es un concepto formal, pues no indica cual es el fundamento del juicio de reproche, es decir, no explica el por qué se le reprocha al sujeto la realización de la acción típica y antijurídica. De esta forma, para responder a esta interrogante, surge la noción material de culpabilidad que establece como fundamento de la reprochabilidad, la capacidad del sujeto de obrar de otro modo. Así, una acción típica y antijurídica sólo es culpable si el sujeto, en la situación concreta en la que se hallaba, podía haber obrado de acuerdo con las exigencias del ordenamiento jurídico. Luego, el concepto material de culpabilidad entro en crisis en la moderna Ciencia del Derecho penal por considerarse que es imposible la comprobación empírica de si el delincuente en la situación concreta en la que se situaba, podría o no haber obrado de otro modo. Sobre éste paradigma CEREZO MIR, José, "El Delito como acción culpable", $A D P C P$, Tomo XLIX, Fascículo I, Enero- Abril (1996), pp. 9 y ss. RIGHI, Esteban, La culpabilidad en materia penal, Buenos Aires: Ad- Hoc, 2003, pp. 19 y ss. GARCÍA ARÁN, "Culpabilidad, legitimidad y proceso", cit. nota $\mathrm{n}^{\circ}$ 46, pp. 71 y ss. TORIO LOPEZ, Ángel, "El concepto individual de culpabilidad”, ADPCP, Tomo XXXVIII, Fascículo II, Mayo- Agosto (1985), pp. 285-301. HORMAZABAL MALAREE, Hernán, “Una necesaria revisión del concepto de culpabilidad". En, AA.VV., Homenaje al Profesor Dr. Gonzalo Rodríguez Mourullo, Agustín Jorge Barreiro compilador, Madrid: Civitas- Aranzadi ediciones, 2005, pp. 493-512. 


\section{Polít. crim. Vol. 4, № 8, (Diciembre 2009), Art. 1, pp. 266-291 (1-26). [http://www.politicacriminal.cl/Vol_04/n_08/Vol4N8A1.pdf]}

cumplen, pudiendo cumplirlas, ello se les debe reprochar retributivamente de una manera proporcional.

Dicho de otro modo, tanto la culpabilidad y su correlato natural, es decir, la retribución penal, se fundamentan en el abuso que el individuo hace de su libre albedrío o capacidad de autodeterminación al momento de delinquir. Por lo mismo, la determinación de la cuantía de la pena en la medida de la culpabilidad ha de proporcionar la pauta vinculante. ${ }^{52}$

Así las cosas, -parafraseando a Schümemann- ${ }^{53}$ podríamos asumir que el criterio al cual adscriben mayoritariamente nuestros tribunales de justicia al tiempo de aplicar la pena, permite configurar en Chile la existencia de un verdadero "Derecho Penal de Retribución de la Culpabilidad". 54

Establecido lo anterior, nuestra judicatura, siendo coherente con sus dictámenes y a fin de mantener -en general- la concordancia con sus lineamientos, ha señalado expresamente la idea retributiva que subyace en determinadas instituciones o tópicos jurídico-penales de importancia.

5.1.1. La reincidencia como manifestación de la idea predominantemente retributiva de la pena en la jurisprudencia.

En materia de reincidencia, la I. Corte de Apelaciones de Santiago ha fallado que

\footnotetext{
${ }^{52}$ La mayoría de la doctrina esta conteste en señalar que asistimos hoy en día a una crisis profunda en lo que concierne al fundamento de la culpabilidad. La llamada teoría general de la culpabilidad, al tiempo de instaurarse, supuso una rectificación del punto de vista "clásico", según el cual la cual la culpabilidad debe materialmente concebirse como la posibilidad -al alcance del autor- de obrar de modo diverso a como lo hizo. De ahí su importancia, pues, de la comprensión del elemento material depende en definitiva la comprensión de la culpabilidad, como dato o materia que conduce a la aplicación de una pena entendida como retribución, o bien, como prevención. Al respecto, Vid. KÜNSEMÜLLER LOEBENFELDER, Carlos, Culpabilidad y Pena, Santiago: Editorial Jurídica de Chile, 2001. pp. 87 y ss. CREUS, Carlos, "La culpabilidad y la pena en la actual doctrina penal". En, Teorías actuales en el Derecho penal. $75^{\circ}$ Aniversario del código penal, Buenos Aires: Ad- Hoc, 1998, pp. 275-289.

${ }^{53}$ SCHÜNEMANN, Bernd, "La Función del Principio de Culpabilidad en el Derecho Penal Preventivo", en AA.VV., El sistema moderno del Derecho penal: Cuestiones fundamentales. Estudios en honor de Claus Roxin en su $50^{\circ}$ Aniversario. Introducción, traducción y notas de Jesús María Silva Sánchez, Madrid: Tecnos, 1991, pp. 147 y ss.

${ }^{54}$ Sobre la culpabilidad en Chile es conveniente resaltar por su rigurosidad científica y académica a los profesores Carlos Künsemüller y Miguel Soto, quienes, matizando los elementos dogmáticos y jurisprudenciales que giran en torno a éste instituto, han hecho aportes de envergadura para desentrañar el posicionamiento que tiene la culpabilidad en nuestro país. En tal sentido, Vid. KÜNSEMÜLLER LOEBENFELDER, Carlos, "El Principio de Culpabilidad en el Derecho Penal Chileno". En, AA.VV., Homenaje al Dr. Marino Barbero Santos: "In memoriam". Coord. ARROYO ZAPATERO, Luis; VERDUGO GÓMEZ DE LA TORRE, Ignacio, Ediciones de la Universidad de Castilla La Mancha, Vol. 1, 2001, pp. 1079-1098. SOTO PIÑEIRO, Miguel, "Una Jurisprudencia Histórica: Hacia el Reconocimiento del Principio de Culpabilidad en el Derecho Penal Chileno", Revista de Derecho de la Universidad Finis Terrae, t. III (1999).
} 
DURÁN, Mario. “Justificación y legitimación político-criminal de la pena. Concepto, criterios y orientaciones en la actual jurisprudencia nacional".

“(...) la única razón aceptable para aumentar la pena al reincidente, consiste en la insuficiencia relativa de la pena ordinaria o castigo efectivamente sufrido en prisión por el reo con anterioridad. Cree en efecto -como ya señalara Carrara en su programa de Derecho Criminal- que cuando un condenado después de haber experimentado un sufrimiento efectivo, vuelve a delinquir, da una señal manifiesta de que desprecia ese sufrimiento y que para él no es pena suficiente esa suma de penas. El mismo autor, sobre este punto relativo a la reincidencia, añade: Se presume la insuficiencia relativa de la fuerza física objetiva de la pena, a causa de la insensibilidad que ante el mal padecido demuestra el delincuente. Por lo tanto, a causa de la naturaleza de ese individuo, excepcionalmente más insensible, hay que aumentar el castigo si se quiere esperar razonadamente un efecto útil". 55

Refrendando éste mismo criterio, la jurisprudencia ha señalado que

"en cuanto al fundamento de la reincidencia, la escuela clásica plantea que el nuevo delinquimiento, pese al castigo sufrido, demuestra que la sanción no era suficientemente severa como para disuadir al agente de cometer otros delitos; y aunque para los positivistas lo verdaderamente importante es la peligrosidad que ha de procurarse contener o evitar, y no la reincidencia misma, es lo cierto que este punto de vista parte de la base de que la pena se haya cumplido en el caso del reincidente". ${ }^{56}$

Nótese que, según el criterio antes indicado, la ponderación penal superior del reincidente obedecería, no directamente a un criterio útil de prevención general, sino a una merma en el quantum de la primera pena aplicada al infractor. En tal sentido, dado que la valoración de la intensidad del primer juicio de reproche irrogado al infractor, no fue lo suficientemente proporcional y retributiva a su culpabilidad, éste, aprovechando tal circunstancia insistiría en desarrollar una reiteración de su conducta delictual. ${ }^{57}$

Ello, al decir de uno de nuestros propios clásicos como Alejandro Fuenzalida implica que

“(...) el legislador atendiendo a que no tiene una medida exacta para penar los delitos, puede i debe aumentar la pena de los delincuentes que estando cumpliendo una condena o que después de haberla quebrantado delinquen de nuevo e igualmente la de los culpables que habiendo sido castigados anteriormente cometen otra vez un delito de igual o distinta especie; porque esta conducta hace presumir que para ellos las penas comunes no han sido eficaces ni proporcionadas a su inmoral obstinación". 58

\footnotetext{
${ }^{55}$ Corte de Apelaciones de Santiago. Fallo Causa Rol № 60305-2001, de 16 de noviembre de 2004. En Gaceta Jurídica $N^{\circ}$ 293, 2004, p. 176. De forma idéntica, de la misma Corte. Fallo Causa Rol N 56389-2002, de 6 de diciembre de 2004. Gaceta Jurídica № 294 (2004), p. 176-177.

${ }^{56}$ Corte Suprema. Fallo Causa Rol No 2345-1997, de 28 de agosto de 1997. En términos idénticos. Corte de Apelaciones de Talca. Fallo Causa Rol N 324.790- 2000, de 8 de agosto de 2000.

57 Como expresa el profesor Garrido Montt, "En nuestra legislación el fundamento que respalda la reincidencia es el mismo que consideraban los clásicos: si un individuo sufrió un castigo por haber cometido un delito y con posterioridad vuelve a delinquir, quiere decir que la pena no fue lo suficientemente drástica para enmendarlo". GARRIDO MONTT, Derecho Penal. Parte General, cit. nota n 36, p. 207.

${ }^{58}$ FUENZALIDA, Alejandro, Concordancias y Comentarios del Código Penal Chileno, Lima:1883, p. 109.
} 


\section{Polit. crim. Vol. 4, № 8, (Diciembre 2009), Art. 1, pp. 266-291 (1-26). \\ [http://www.politicacriminal.cl/Vol_04/n_08/Vol4N8A1.pdf]}

Por lo mismo es posible sostener que, detrás de la reincidencia -en cuanto figura agravante-, aflora claramente la noción de retribución penal, pues, como se explicó, el elemento histórico-legitimador de tal figura arranca precisamente de su vinculación con los fines de la pena. ${ }^{59}$

\subsection{Recientes manifestaciones eclécticas de la idea predominantemente retributiva de la pena en la jurisprudencia.}

Por otra parte, y en menor medida, nuestra jurisprudencia también se ha pronunciado en la individualización concreta de la pena desde un punto de vista preventivo sin abandonar, en todo caso, la noción retributiva de la pena.

Así, la Excelentísima Corte Suprema, conociendo vía casación en el fondo respecto de una causa sobre violación de DD.HH y, aplicando los Convenios de Ginebra, ha manifestado que:

“(...) respecto de hechos de esta clase, cobra importancia fundamental la función de prevención general de las reacciones punitivas, la cual exige que las amenazas contenidas en las normas correspondientes se hagan efectivas en cualquier momento en que la persecución de los responsables se haga posible y aunque la prevención especial parezca ya satisfecha porque el transcurso del tiempo haya convertido a los infractores en ciudadanos inofensivos. La sociedad, en efecto, no toleraría que violaciones de tal magnitud queden definitivamente impunes, con el pretexto de que el castigo ya no puede resocializar al que no está más en condiciones de reincidir pues, no obstante ello, sí puede actuar reforzando para el futuro en los ciudadanos el respeto por los valores elementales sobre los que descansa la posibilidad de una convivencia pacifica (prevención general positiva) y disuadiendo a quienes se sientan inclinados a incurrir en hechos semejantes (prevención general negativa). Más aún cuando, "frente a la negación que el delito representa de los valores consagrados por una comunidad y a cuya preservación considera ésta ligada su razón de ser y su organización y acción política y jurídica, el derecho Penal los reafirma mediante la reprobación y el reproche de los actos que los niegan, expresando y concretando tal reafirmación en su punición, es decir, denotando de manera simbólica con ella la permanencia, en la sociedad, de sus aspiraciones valorativas y sus ideales de vida" (Manuel de Rivacoba y Rivacoba: "La Retribución Penal, Editorial Jurídica Cono Sur Ltda., Santiago, Chile, año mil novecientos noventa y cinco, página 63$)$ ". ${ }^{60}$

El precedente razonamiento del máximo Tribunal, de manera evidente, plasma un nuevo criterio ecléctico o unitario de los fines de la pena. En efecto, dicho fallo parte prima face de la premisa que la norma penal es, en su faz de determinación judicial, aplicada con la

\footnotetext{
${ }^{59}$ Sobre el particular Vid. CARRARA, Francesco, Programa de Derecho Criminal, II, Trad.: ORTEGA, José; GUERRERO, Jorge, Bogotá: 1957, p. 207. VALLEJOS, Jaen, "Reincidencia y Derecho Penal de Culpabilidad". En, Política Criminal y Reforma Penal: Homenaje a la Memoria del Prof. Dr. D. Juan del Rozal, 1993, pp. 715-724. HAFFKE, Bernhard, "Reincidencia y Medición de la Pena". En, AA.VV., El sistema moderno del Derecho penal, cit. nota $\mathrm{n}^{\circ} 53$, pp. 179 y ss. KÜNSEMÜLLER LOEBENFELDER, Carlos, "La Circunstancia Agravante de Reincidencia", Gaceta Jurídica № 212 (1998), pp. 61 y ss.

${ }^{60}$ Corte Suprema. Fallo Causa Rol No 3125-2004, de 13 de marzo de 2007.
} 
DURÁN, Mario. “Justificación y legitimación político-criminal de la pena. Concepto, criterios y orientaciones en la actual jurisprudencia nacional".

intensión directa de dirigir a la comunidad -en general- a lo menos dos mensajes determinados.

El primero de ellos, destinado a inhibir al conglomerado a la comisión de hechos delictuosos, es decir, a comunicarles mediante la aplicación de sanciones penales la no realización de la conducta tipificada en la ley. El segundo, en tanto, destinado a transmitirles confianza y fidelidad hacia el ordenamiento, confirmando y reforzando -de paso- el respeto de los valores elementales sobre los que descansa la convivencia pacifica.

Como se ve, éste criterio preventivo general -en su faz negativa y positiva-ha de ser el motor que guíe la imposición de la pena en un estadio mediato. Sin embargo, la reafirmación de la punición no sólo se lograría mediante la comunicación -abstractamente considerada- entre sentenciador y la comunidad, sino que, además, es imprescindible la reprobación y reproche del acto delictual mismo. ${ }^{61}$

La retribución, así entendida, aparecería como el tópico que daría pie a que se logren los cometidos preventivos generales buscados siendo, en consecuencia, el fin inmediato de la reacción; ${ }^{62}$ puesto que

"con las molestias y las limitaciones que le son naturales, subordinada en todo caso a la índole y función retributiva (...), nada obsta a que la pena ofrezca y que se provean los medios para que ejerza una acción preventiva, de cualquier forma, en cualquier momento, y en particular dentro de la etapa capital que es su ejecución". ${ }^{63}$

\subsection{Problemática de la prevención especial en la etapa de ejecución de la pena en la jurisprudencia.}

\footnotetext{
${ }^{61}$ Sobre la imposición del mal penal como elemento preventivo y retributivo del juicio de reproche, Vid. VON HIRSCH, Andrew, "Retribución y Prevención Como Elementos de Justificación de la Pena. En, Critica y Justificación de Derecho Penal en el Cambio de Siglo. Ediciones de la Universidad de Castilla- La Mancha. Cuenca, 2003, pp. 125 y ss.

${ }^{62}$ En un sentido similar -aunque no idéntico-, la Corte de Apelaciones de San Miguel, pronunciándose respecto de la concesión de ciertos beneficios en materia de microtráfico señaló que: "si el legislador hubiera querido aplicar el beneficio en comento se habría incorporado en el microtráfico este beneficio; y, (...), porque de llegar a la conclusión contraria, la sanción sería desproporcionada, irrisoria y disminuida frente a la gravedad del hecho punible y a la principal finalidad del castigo, que es prevenir la reiteración de tal conducta". Corte de Apelaciones de San Miguel. Fallo Causa Rol No 1702-2007, de 10 de diciembre de 2007. ${ }^{63}$ DE RIVACOBA Y RIVACOBA, Función y Aplicación de la Pena, cit. nota ${ }^{\circ}$ 49, p. 46. En este aspecto es de hacer notar que, para el citado autor, en un primer momento los conceptos de retribución y prevención constituyen una verdadera y perfecta antítesis, y, por tanto, no admiten ningún grado de conciliación entre sí. Sus respectivos contenidos, la imagen del hombre y de la sociedad que uno y otro suponen, y los correspondientes fundamentos y condicionamientos políticos que los sustentan y envuelven, son por completo contradictorios, o sea, recíprocamente excluyentes, y, con ello, hace, también, que en sus efectos y consecuencias resulten antitéticos. Empero, acto seguido, reconoce que en la actualidad hay una lazo evidente entre la naturaleza retributiva de la pena y su función de prevención general de los delitos. DE RIVACOBA Y RIVACOBA, Manuel, La Retribución Penal, Santiago: Editorial Jurídica Conosur Ltda, 1995., pp. 41 y ss. DE RIVACOBA Y RIVACOBA, Función y Aplicación de la Pena, cit. nota n 49, pp. 43 y ss.
} 
Polit. crim. Vol. 4, No 8, (Diciembre 2009), Art. 1, pp. 266-291 (1-26).

[http://www.politicacriminal.cl/Vol_04/n_08/Vol4N8A1.pdf]

Por último, debe señalarse que nuestra jurisprudencia ha sido extremadamente escueta a la hora de fundamentar la pena en consideración a fines preventivo-especiales.

Así, dividiéndose en etapas de ponderación judicial y ejecutiva la aplicación de la pena, se ha declarado que

"no obstante, la obligación que impone la misma Carta Fundamental vigente del año 1980, en el inciso $5^{\circ}$, del n ${ }^{\circ} 3$ del artículo 19 , en orden a que se brinden las garantías de un justo y racional procedimiento, hace patente el deber de los órganos del Estado, en especial de los Tribunales de Justicia, para resguardar en el ejercicio de las potestades jurisdiccionales, que en la individualidad de la pena se respeten ciertos derechos o garantías substanciales mínimas, como ser los principios rectores del debido proceso, la formulación de una sentencia informada en aquellos principios con los resguardos que impidan los errores y abusos, la aplicación de una sanción condigna y proporcionalmente retributiva al hecho reprochado y, por último, la ejecución de la pena teniendo en cuenta los objetivos perseguidos por medio de la punición estatal, entre otros la resocialización o rehabilitación de los condenados". 64

De lo anterior se desprende una nítida diferenciación en estados o etapas en las cuales la pena ha de ser cumplir una función determinada. Así, según el razonamiento precedente, es en la fase de ejecución de la pena -encomendada en nuestro país a Gendarmería de Chileen donde han de primar los intereses de orden preventivo especial, que permitan al condenado lograr una resocialización o rehabilitación en el medio social, pues, en la fase de conminación judicial - anterior a la de ejecución- lo que rige es la idea retributiva y proporcional de la pena.

Por último, en atención al cariz puramente preventivo especial de la pena, ${ }^{65}$ es dable formular que la judicatura nacional, en atención a las especiales consideraciones que el cumplimiento de una eventual condena supone en los mal llamados Centros de Reinserción Social ha manifestado que,

"uno de los elementos importantes de la pena o reacción social, además del castigo mismo del culpable y de la prevención de nuevos delitos, es la corrección del delincuente entendida como la reforma o regeneración intima de la voluntad perversa de éste, de forma que su conducta futura corresponda a una verdadera rectitud interna, objetivo muy difícil de lograr ya en medios penitenciarios normales, pero más aún o casi imposible en recintos que eventualmente, por el hacinamiento, permiten la

\footnotetext{
${ }_{65}^{64}$ Corte de Apelaciones de San Miguel. Fallo causa Rol No 3361- 2003, de 12 de mayo de 2004.

${ }^{65}$ Sobre el particular, Vid. GARCIA PABLOS DE MOLINA, Antonio, "La Supuesta Función Resocializadora del Derecho Penal: Utopía, Mito y Eufemismo". ADPCP, Tomo XXXII, Fascículo III, Septiembre- Diciembre, MCMLXXIX., pp. 645 y ss. CURY URZUA, Enrique, "La Prevención Especial Como Límite de la Pena". ADPCP, Tomo XLI, Fascículo III, Septiembre-Diciembre, MCMLXXXVIII., p. 685. MAPELLI CAFARENA, Borja; TERRADILlOS BASOCO, Juan, Las Consecuencias Jurídicas del Delito, Madrid: Civitas, 1996, pp. 126 y ss.
} 
DURÁN, Mario. “Justificación y legitimación político-criminal de la pena. Concepto, criterios y orientaciones en la actual jurisprudencia nacional".

realización de actos aberrantes, que producen una clara degeneración moral en los internos, al mantenerlos en grupos en celdas demasiado pequeñas". ${ }^{6}$

En tal línea argumental no cabe sino concluir que, para ningún sector de la sociedad chilena -ni menos para los tribunales de justicia- pasa desapercibido el hecho nuestro sistema carcelario, en lo fáctico, se vincula más a un sistema desocializador que a uno integrador. Esto es, en la clásica definición de von Liszt, un sistema inocuizador para el delincuente antisocial peligroso. ${ }^{67}$

\section{Conclusión.}

De las manifestaciones jurisprudenciales arriba señaladas, no cabe duda que la determinación judicial de la pena, en su esencia, se encuentra cohesionada con el ejercicio de la función jurisdiccional, pues, quién "dice" el Derecho, interpretando el supuesto de hecho y aplicando la consecuencia normativa es, en definitiva, el juez.

Por lo mismo, ¿Cuál es el criterio que nuestros tribunales han adoptado para justificar el fin de la pena?, ¿Es posible inferir, a propósito de la labor hermenéutica desarrollada por los jueces, un fin que sea el dominante?, ¿Existen en la praxis judicial pronunciamientos sistemáticos sobre la nociones de retribución y prevención?

Éstas y otras preguntas, de momento, no tienen -ni en lo teórico ni en lo práctico- una respuesta única. En primer término, porque la dogmática penal nacional -en general- sólo ha vertido sus esfuerzos en estudios primordialmente doctrinarios que, la mayoría de las veces, prescinden del examen de fuentes empíricas que demuestren la verosimilitud de lo trazado hipotéticamente; además, en segundo término, porque nuestra jurisprudencia -en su mayoría-, ha soslayado el razonamiento que debería ser, motivo y fundamento, del fin a propósito del cual se debería legitimar la imposición de una pena en nuestro sistema punitivo. $^{68}$

Por estas razones, uno de los principales problemas dogmáticos para una búsqueda y determinación de fines de la pena en Chile es, precisamente, la falta de una clara decisión

\footnotetext{
${ }^{66}$ Corte de Apelaciones de Santiago. Fallo causa Rol No 56.616- 2002, de 28 de octubre de 2002; Confirmado por la Excelentísima Corte Suprema, con fecha 4 de noviembre de 2002.

${ }^{67}$ VON LISZT, Franz, La idea del fin en Derecho Penal. Programa de la U. de Marburgo, 1882. Introd. y nota biográfica de J.M. Zugaldía Espinar. Trad.: PÉREZ DEL VALLE, Carlos, Granada: Comares, 1995.

${ }^{68}$ Con lo expresado, no debe pensarse que el déficit argumentativo jurisprudencial existente en nuestro país, es un problema que sólo a nosotros nos atañe. Por el contrario, es un denominador común que se verifica en casi la mayoría de las legislaciones. Al respecto se señala que: "La racionalidad de un sistema sancionador depende no sólo de la racionalidad abstracta de las leyes sino también del modo en que se lleva a cabo la función jurisdiccional de imponer y ejecutar las sanciones. La realidad, sin embargo, demuestra que a menudo el propio juez tiene una insuficiente conciencia del papel que ejerce. Es preocupante en España en déficit de motivación de la pena en la jurisprudencia (...) es una situación en la que el juez abdica de su responsabilidad sin dejar de ejercer el poder discrecional que la ley le otorga, favorecido por un clima intelectual y una cultura procesal que ha despreciado a menudo la importancia central de las cuestiones penológicas". TAMARIT SUMALLA, Josep M., "Sistema de Sanciones y Política Criminal. Un Estudio de Derecho Comparado Europeo". Revista Electrónica de Ciencia Penal y Criminología. 2007, núm. 09-06, p. 5.
} 
Polit. crim. Vol. 4, No 8, (Diciembre 2009), Art. 1, pp. 266-291 (1-26).

[http://www.politicacriminal.cl/Vol_04/n_08/Vol4N8A1.pdf]

del legislador en orden a determinar la orientación o el fin de la pena. Cuestión que, sin perjuicio de las sentencias arriba descritas, dificulta o constriñe duramente al sentenciador para expresarse y explayarse en este tema al fundamentar la sentencia en el caso concreto. Así, a mi juicio, no le queda más que recurrir a la clásica visión que subyace, naturalmente por lo demás, en nuestro clásico Código Penal de 1874.

Desde esta óptica, en consecuencia, doy por asumido que el ideal de racionalidad que debería gobernar la justificación de la pena en nuestro país, no puede ni debe -bajo ningún respecto-, abarcar un cariz reducido únicamente a lo abstracto o lo meramente dogmático, pues, tanto de de lo real y efectivo como de los valores político-criminales, se pueden superar las antinomias que, hoy por hoy, son la piedra de tope para el desarrollo de una democrática, humanitaria y útil fundamentación y justificación de la sanción penal.

\section{BIBLIOGRAFÍA}

ANTON ONECA, José, "El código penal de 1848 y D. Joaquín Francisco Pacheco", ADPCP, Tomo XVIII. Fascículo III. Madrid, MCMLXV.

BERDUGO GÓMEZ DE LA TORRE, I.-ZÚÑIGA RODRÍGUEZ, L, (Coord.) Manual de Derecho Penitenciario. Salamanca-Colex: Colex, 2001.

BARBERO SANTOS, Marino, "La fundamentación doctrinal y la orientación político-criminal del Código Penal Chileno en el panorama actual del Derecho Penal" en Actas de las Jornadas Internacionales en celebración del centenario del Código Penal Chileno, Edeval 1975, pp. 35 y ss.

BOTTKE, Wilfried. "La actual discusión sobre las finalidades de la pena" en, SILVA SÁNCHEZ, Jesús-María. (Edit.) Política criminal y nuevo Derecho penal. L.H. a Claus Roxin. Barcelona: Bosch, pp. 41 y ss.

BUSTOS RAMÍREZ, Juan, Manual de Derecho Penal. Parte General. $3^{\text {a }}$ edición aumentada, corregida y puesta al día. Barcelona: Editorial Ariel, 1989.

BUSTOS RAMÍREZ, J.-HORMAZÁBAL MALARÉE, H., "Pena y Estado", Papers, Revista de Sociología $\mathrm{n}^{\circ} 13$ (1980), pp. 97 y ss.

CARRARA, Francesco, Programa de Derecho Criminal, II, ORTEGA, José; GUERRERO, Jorge (Trads.), Bogotá, 1957.

CEREZO MIR, José, "El Delito como acción culpable”, ADPCP, Tomo XLIX, Fascículo I, EneroAbril, 1996.

, Curso de Derecho penal español. Parte General. I. Introducción. Teoría del Delito/1. $4^{\mathrm{a}}$ reimpresión de la $3^{\mathrm{a}}$ ed. de 1985. Madrid: Tecnos, 1992.

CREUS, Carlos, "La culpabilidad y la pena en la actual doctrina penal" en Teorías actuales en el Derecho penal. 75 Aniversario del código penal. Buenos Aires: Editorial Ad- Hoc, 1998.

CURY URZUA, Enrique, Derecho Penal. Parte General, Tomo II. Segunda Edición Actualizada. Santiago: Editorial Jurídica de Chile, 1992. 
DURÁN, Mario. “Justificación y legitimación político-criminal de la pena. Concepto, criterios y orientaciones en la actual jurisprudencia nacional".

, "La Prevención Especial Como Límite de la Pena", ADPCP, Tomo XLI, Fascículo III, Septiembre-Diciembre, MCMLXXXVIII.

DE RIVACOBA Y RIVACOBA, Manuel, Evolución Histórica del Derecho Penal Chileno. Valparaíso: Editorial Edeval, 1991. , Función y Aplicación de la Pena. Buenos Aires: Ediciones Depalma, 1993. , La Retribución Penal. Santiago: Editorial Jurídica Conosur Ltda., 1995.

ETCHEBERRY, Alfredo, Derecho Penal. Parte General. Tomo Segundo. Tercera Edición Revisada y Actualizada. Santiago: Editorial Jurídica de Chile, 1998.

FEIJOO SANCHEZ, Bernardo, "Individualización de la pena y teoría de la pena proporcional al hecho. El debate europeo sobre los modelos de determinación de la pena", InDret Revista para el análisis del Derecho 1 (2007), pp. 2 y ss.

FERRAJOLI, Luigi, Derecho y Razón. Teoría del Garantismo Penal. Madrid: Editorial Trotta, 1995.

FRANK, Reinhard, Sobre la Estructura del Concepto de Culpabilidad. Buenos Aires: Editorial B de F., 2002.

FUENZALIDA, Alejandro, Concordancias y Comentarios del Código Penal Chileno, Lima, 1883.

GARCÍA ARÁN, Mercedes, "Culpabilidad, legitimidad y proceso", ADPCP, Tomo XLI, Fascículo I (1998).

GARCIA PABLOS DE MOLINA, Antonio, Introducción al Derecho penal. Cuarta edición. Madrid: Editorial Universitaria Ramón Areces, 2006.

, "La Supuesta Función Resocializadora del Derecho Penal: Utopía, Mito y Eufemismo", $A D P C P$, Tomo XXXII, Fascículo III, SeptiembreDiciembre, MCMLXXIX.

, "Tendencias del actual Derecho penal" en, VV.AA.

Modernas tendencias en la ciencia del Derecho penal y en la Criminología. Madrid: UNED, 2001, pp.39 y ss.

GARIDO MONTT, Mario, Derecho Penal. Parte General, Tomo I. Santiago: Editorial Jurídica de Chile, 1997.

GIMBERNAT ORDEIG, Enrique, “¿Tiene futuro la dogmática jurídicopenal?” en: EL MISMO, Estudios de Derecho penal. Madrid: Civitas, 1976. pp. 57 y ss. Y, en: Problemas actuales de las ciencias penales y la filosofía del Derecho. L.H. al profesor Luis Jiménez de Asúa. Buenos Aires: Pannedille, 1970, pp. 595 y ss.

GOLDSCHMIDT, James, La Concepción Normativa de la Culpabilidad. DE GOLDSCHMIDT, Margarethe; NUÑEZ, Ricardo (Trads.), Segunda Edición. Buenos Aires: Editorial B de F, 2002.

HORMAZABAL MALAREE, Hernán, “Una necesaria revisión del concepto de culpabilidad”. En: AA.VV. Homenaje al Profesor Dr. Gonzalo Rodríguez Mourullo. BARREIRO, Agustín Jorge (Comp.) Madrid: Civitas- Aranzadi ediciones, 2005.

JESCHECK, Hans-Heinrich, Tratado de Derecho Penal. Parte General. MANZANARES SAMANIEGO, José Luis (Trad.) Granada: Comares Editorial, 1993. 
Polit. crim. Vol. 4, No 8, (Diciembre 2009), Art. 1, pp. 266-291 (1-26).

[http://www.politicacriminal.cl/Vol_04/n_08/Vol4N8A1.pdf]

KÜNSEMÜLLER, Carlos, Culpabilidad y Pena. Prologo de Alfredo Etcheberry. Santiago: Editorial jurídica de Chile, 2001.

, "El Principio de Culpabilidad en el Derecho Penal Chileno". En:

AA.VV. Homenaje al Dr. Marino Barbero Santos: "In memoriam". ARROYO ZAPATERO, Luis; BERDUGO GÓMEZ DE LA TORRE, Ignacio (Coords.), Ediciones de la Universidad de Castilla La Mancha, Vol. 1, 2001, pp. 1079-1098.

, "La Circunstancia Agravante de Reincidencia", Gaceta Jurídica $\mathrm{N}^{\mathrm{o}}$

212, pp. 61 y ss.

MAGARIÑOS, Mario, "Hacia un Criterio Para la Determinación Judicial de la Pena". En: AA.VV., Determinación Judicial de la Pena. Buenos Aires: Editores del Puerto, 1993.

MAPELLI CAFARENA, Borja; TERRADILLOS BASOCO, Juan, Las Consecuencias Jurídicas del Delito. Madrid: Civitas, 1996.

MATUS ACUÑA, Jean Pierre, "Fernández, Fuenzalida y Vera: Comentaristas, autodidactas y olvidados. Análisis diacrónico y sincrónico de la doctrina penal chilena del siglo XIX”. Ius et Praxis, Vol. 12, N¹ (2006), ISSN 0718-0012, pp. 31-67.

MEZGER, Edmund, Derecho Penal. Libro de Estudio. Parte General. Buenos Aires: Editorial Bibliográfica Argentina, 1958.

MIR PUIG, Santiago, Introducción a las Bases Del Derecho penal. Buenos Aires: Editorial B de F., 2003.

MUÑOZ CONDE, Francisco, Edmund Mezger y el Derecho Penal de su Tiempo. Estudios Sobre el Derecho Penal en el Nacionalsocialismo. Valencia: Editorial Tirant lo Blanch, 2003.

PACHECO, Joaquín Francisco, Estudios de Derecho Penal. Lecciones pronunciadas en el Atenéo de Madrid. Tomo primero. Madrid: Boix Editor, 1842.

POLITOFF, Sergio, "Fines de la Pena y Racionalidad en su Imposición”, Ius Et Praxis, año 4, No 2 (1998).

QUINTERO OLIVARES, Gonzalo, "Determinación de la Pena y Política criminal”, $C P C, \mathrm{n}^{\circ} 4$ (1982), pp. 49 y ss.

RIGHI, Esteban, La culpabilidad en materia penal, Buenos Aires: Editorial Ad- Hoc, 2003.

ROXIN, Claus, "La Determinación de la Pena a la Luz de la Teoría de los fines de la Pena". En: EL MISMO, Culpabilidad y Prevención en el Derecho Penal. MUÑOZ CONDE, Francisco (Trad.). Madrid: Editorial Reus S.A., 1981.

, "Reflexiones Político-Criminales Sobre el Principio de Culpabilidad". En: EL MISMO, Culpabilidad y Prevención en el Derecho Penal.

, "Franz von Liszt y la concepción políticocriminal del Proyecto Alternativo". En: EL MISMO, Problemas básicos del Derecho penal, pp. 37 y ss.

SCHÜNEMANN, Bernd, "La Función del Principio de Culpabilidad en el Derecho Penal Preventivo". En: AA.VV., El sistema moderno del Derecho penal: Cuestiones fundamentales. Estudios en honor de Claus Roxin en su $50^{\circ}$ Aniversario. Introducción, traducción y notas de Jesús María Silva Sánchez. Madrid: Editorial Tecnos, 1991, pp. 10791098 .

, “Aporías de la teoría de la pena en filosofía. Pensamientos sobre Inmanuel Kant” InDret 2 (2008), pp. 2 y ss. 
DURÁN, Mario. “Justificación y legitimación político-criminal de la pena. Concepto, criterios y orientaciones en la actual jurisprudencia nacional".

SILVA SANCHEZ, Jesús María, Aproximación al Derecho Penal contemporáneo. Barcelona: Bosch, 1992.

, "La Teoría de la Determinación de la Pena como Sistema (Dogmático): Un Primer Esbozo", InDret, № 2 (2007).

SOTO PIÑEIRO, Miguel, "Una Jurisprudencia Histórica: Hacia el Reconocimiento del Principio de Culpabilidad en el Derecho Penal Chileno", R.D.U.F.T., t. III (1999).

TAMARIT SUMALLA, Josep M, "Sistema de Sanciones y Política Criminal. Un Estudio de Derecho Comparado Europeo", Revista Electrónica de Ciencia Penal y Criminología, núm. 09-06 (2007).

TORIO LOPEZ, Ángel, "El concepto individual de culpabilidad", ADPCP, Tomo XXXVIII, Fascículo II, Mayo- Agosto (1985).

VAllejos, Jaen, "Reincidencia y Derecho Penal de Culpabilidad". En: Política Criminal y Reforma Penal: Homenaje a la Memoria del Prof. Dr. D. Juan del Rozal, 1993.

VERA, Robustiano, Código Penal de la República de Chile Comentado. Santiago: Imprenta de P. CADOT I Ca., 1883.

VON HIRSCH, Andrew, "Retribución y Prevención Como Elementos de Justificación de la Pena." En: Critica y Justificación de Derecho Penal en el Cambio de Siglo. Cuenca: Ediciones de la Universidad de Castilla- La Mancha, 2003.

VON LISZT, Franz, La idea del fin en el Derecho penal. Programa de la U.de Marburgo, 1882. Granada: Comares, 1995.

ZAFFARONI, Raúl Eugenio, Tratado de Derecho Penal. Parte General. Tomo V. Buenos Aires: Ediar Editores, 1988.

, En busca de las penas perdidas. Deslegitimación y dogmática jurídicopenal. Buenos Aires: Ediar,1989.

ZIFFER, Patricia, "Consideraciones Acerca de la Problemática de la Individualización de la Pena". En: AA.VV., Determinación Judicial de la Pena. Buenos Aires: Editores del Puerto, 1993. 